\title{
Phytochemistry of genus Polygonatum: A review
}

\author{
Haroon Khan ${ }^{1}$, Abdur Rauf ${ }^{2}$ \\ ${ }^{1}$ Department of Pharmacy, Abdul Wali Khan University, Mardan -23200, Pakistan \\ ${ }^{2}$ Institute of Chemical Sciences, University of Peshawar, Peshawar -25120, Pakistan
}

\section{Email address:}

hkdr2006@gmail.com (H. Khan), mashaljcs@yahoo.com (A. Rauf)

\section{To cite this article:}

Haroon Khan, Abdur Rauf. Phytochemistry of Genus Polygonatum: A Review. American Journal of Biomedical and Life Sciences. Special Issue: Phytochemical and Pharmacological Study of Medicinal Plants. Vol. 3, No. 2-1, 2015, pp. 5-20. doi: 10.11648/j.ajbls.s.2015030201.12

\begin{abstract}
The current review article deals with the comprehensive phytochemical background of genus Polygonatum. It was observed that out of approximately 60 species, only 9 are subject to phytochemical studies that led mostly to the isolation of saponins, phytohormones, glycosides, flavonoids, esters and alkaloids. However, the remaining species are still waiting for exploration.
\end{abstract}

Keywords: Phytochemistry, Polygonatum, Liliaceae, Taxonomic status

\section{Introduction}

Polygonatum (King Solomon's-seal, Solomon's Seal) is a member of family Liliaceae or Convallariaceae consist of approximately 60 species. The various species of the genus are widely distributed in the temperate regions of the East Asia. Specifically in China and Japan, approximately 40 different species of Polygonatum have been reported [1-2]. Additionally it is also found in India, Korea, Nepal, Afghanistan, Bhutan, Nepal and Russia. Along with Asia, Polygonatum also grows in the moderate climate zones of North America and Europe. Flora of Pakistan indicates the presence of four different species of Polygonatum. These include $P$. multiflorum, $P$. geminiflorum, $P$. cirrhifolium and $P$. verticillatum. Polygonatum species are widely distributed in various part of the country like Hazara, Chitral, Swat and Kurram agency [3-4]. They are usually wild perennial rhizomatous herbs [1].

\section{Taxonomic Status}

Table 1. Taxonomic status of Polygonatum

\begin{tabular}{ll}
\hline Kingdom & Animalia \\
\hline Phylum & Platyhelminthes \\
Class & Cestoda \\
Order & Liliales \\
Genus & Polygonatum \\
Family & Liliaceae / Convallariaceae. \\
\hline
\end{tabular}

$[4]$

\section{Phytochemistry of Polygonatum}

Research groups have been reported variety of chemical constituents from the genus Polygonatum primarily saponins, phyto-hormones, glycosides, flavonoids and alkaloids (Table 2).

The secondary metabolites isolated from the species of Polygonatum have demonstrated antimicrobial activity against different pathogens. Kinganone (new indolizinone) and 3-ethoxymethyl-5,6,7,8-tetrahydro-8-indolizinone were isolated from the rhizome of Polygonatum kingianum. Both Kinganone and 3-ethoxymethyl-5,6,7,8-tetrahydro-8indolizinone exhibited antibacterial and antifungal activities in the agar diffusion assay [5]. Similarly, homoisolflavanone, triterpenoids and steroidal saponins were isolated from the rhizomes of $P$. odoratum. These compounds showed outstanding antimicrobial activity against the tested bacteria and fungi [6-7]. The aqueous extract of Polygonatum was found effective against various human pathogenic bacteria. The bacteria were S. typhi, S. aureus and M. tuberculosis [8].

Many studies support the role of Polygonatum in the activation of apoptosis [9-10]. The lectin isolated from the $P$. cyrtonema demonstrated outstanding inhibition against MCF-7 cells. The induction of apoptosis was suggested to be caspase-dependent in nature. Furthermore, it has also been shown that the apoptosis was augmented by autophagy [11]. The Bcl-2 is a protein with significant anti-apoptotic properties. As a therapeutic modality, the modulation of Bcl-2 concentration is an effective approach to treat cancers. The secondary metabolite, 8- 
methyl-dihydrobenzopyrone has been isolated from $P$. odoratum. The compound exhibited prominent anticancer activity in breast cancers by inducing the phosphorylation of Bcl-2. [12]. Most of the saponins isolated from the Polygonatum species have cytotoxic activity. In a phytochemical study, 10 different steroidal saponins and a glycoside were isolated from $P$. zanlanscianense. When analyzed in cytotoxic assay (in vitro) against HeLa cells, all the tested saponins exhibited significant activity while the $\mathrm{IC}_{50}$ was ranges from $3.14-14.57 \mu \mathrm{g} / \mathrm{mL}$ [13]. The saponins isolated from the rhizomes of $P$. sibiricum were tested for cytotoxic potential against human breast cancer cells. The result showed moderate activities of the compounds [14].

The antioxidant potential of Polygonatum has been investigated in comparison with Vitamin E, a known antioxidant [15]. The isolation of a very potent antioxidant like quercetin from $P$. altelobatum [16] providing a strong evidence of the antioxidant potential of Polygonatum.

Secondary metabolites with well-defined analgesic, antipyretic and anti-inflammatory properties have been isolated from Polygonatum. For instance, salicylic acid has been reported from $P$. kingianum [17] a historical analgesic, antipyretic and anti-inflammatory agent [18].

many steroidal saponins have been isolated from Polygonatum including diosgenin and related compounds. Research on diosgenin and related steroidal saponins showed significant anti-inflammatory activity. These compounds nonspecifically inhibited both cyclooxygenase (cyclooxygenase 1 and 2). However, cyclooxygenase-2 was more prominent [19]. The algicidal activity of Polygonatum is also reported in literature [20]. Liquiritigenin and isoliquiritigenin are isolated from P. kingianum [17]. Emodin (1,3,8-trihydroxy-6-methylanthraquinone), an anthraquinone derivative has been isolated from $P$. multiflorum. The compound possesses ameliorating effects on the memory consolidation. For this study, specific animal model was used in which cycloheximide-dependent memory consolidation impairment in rats. The result was produced by the induction of serotonergic 5- $\mathrm{HT}_{1} \mathrm{~A}$-receptor partial agonist and $5-\mathrm{HT}_{2}$ receptor antagonist. However, the muscarinic receptor antagonist showed negative activity [21].

Table 2. List of compounds isolated from genus Polygonatum

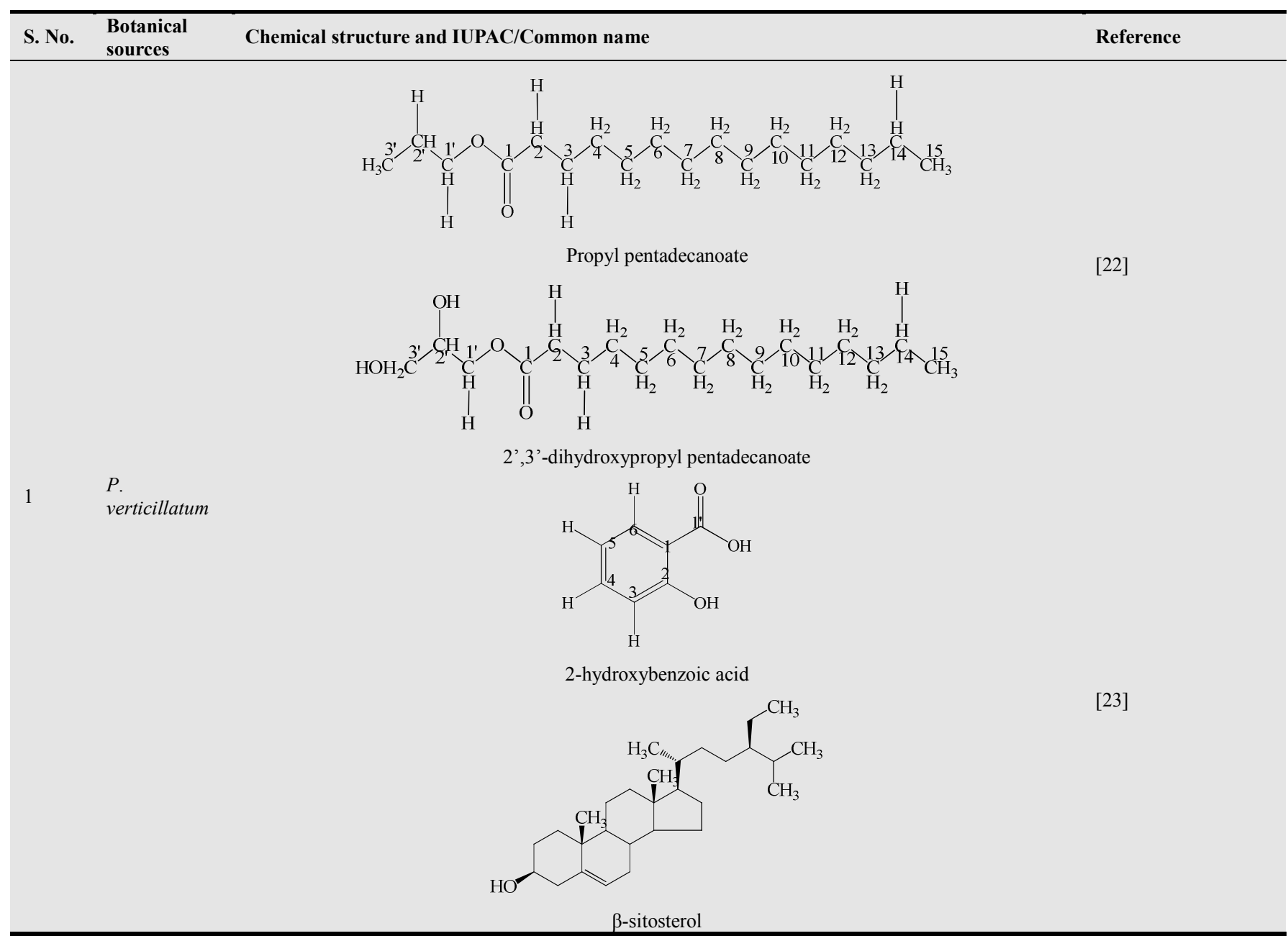




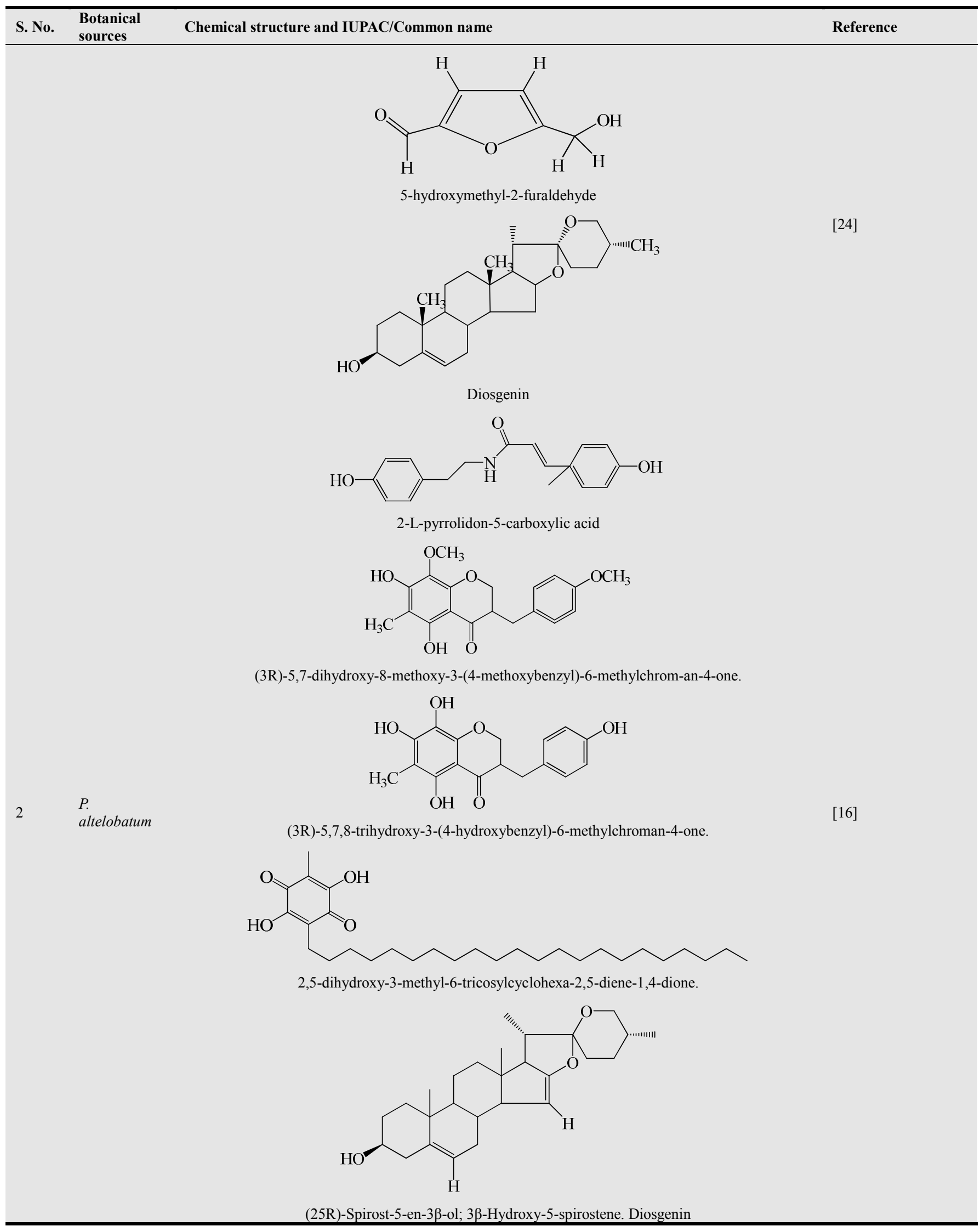




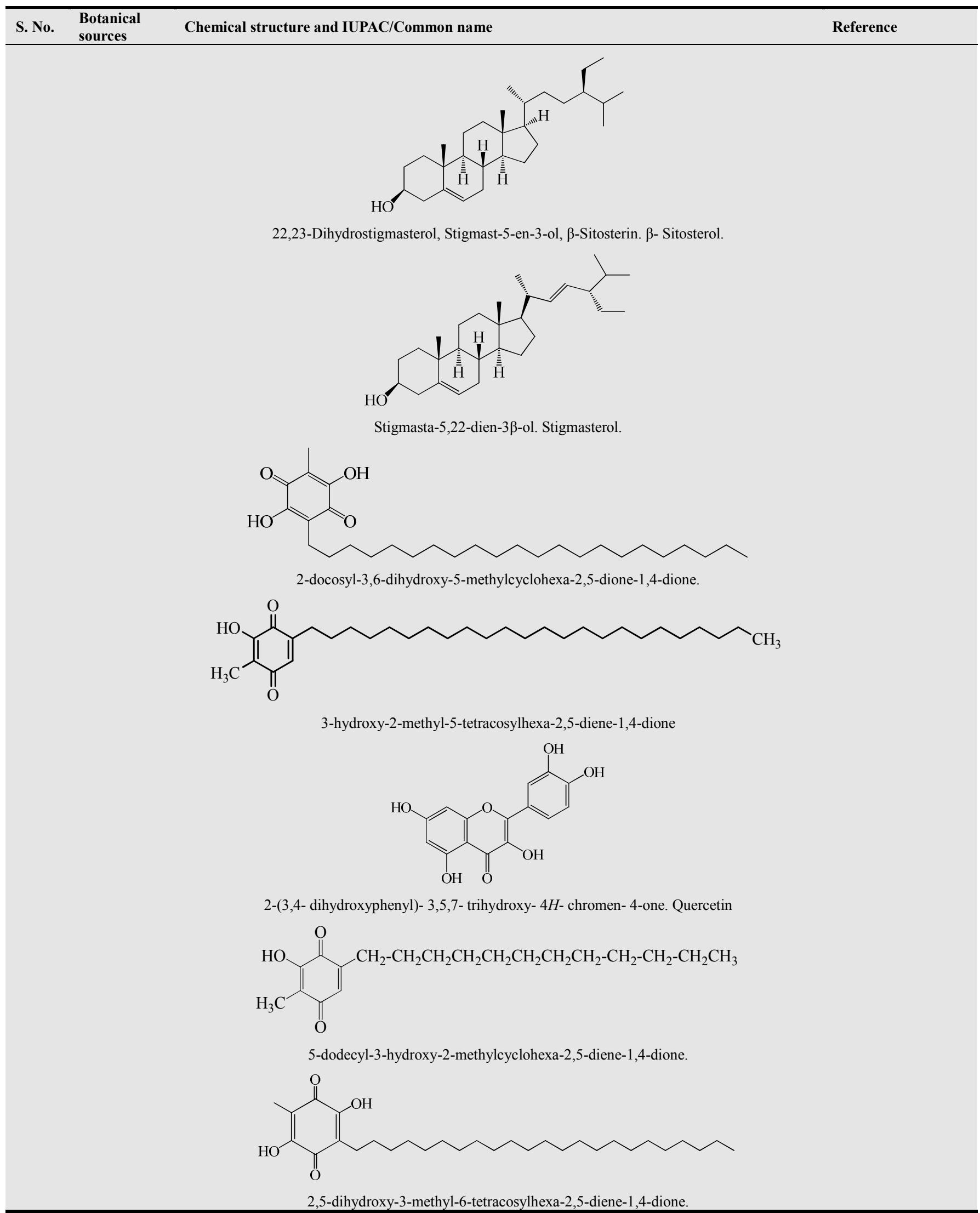




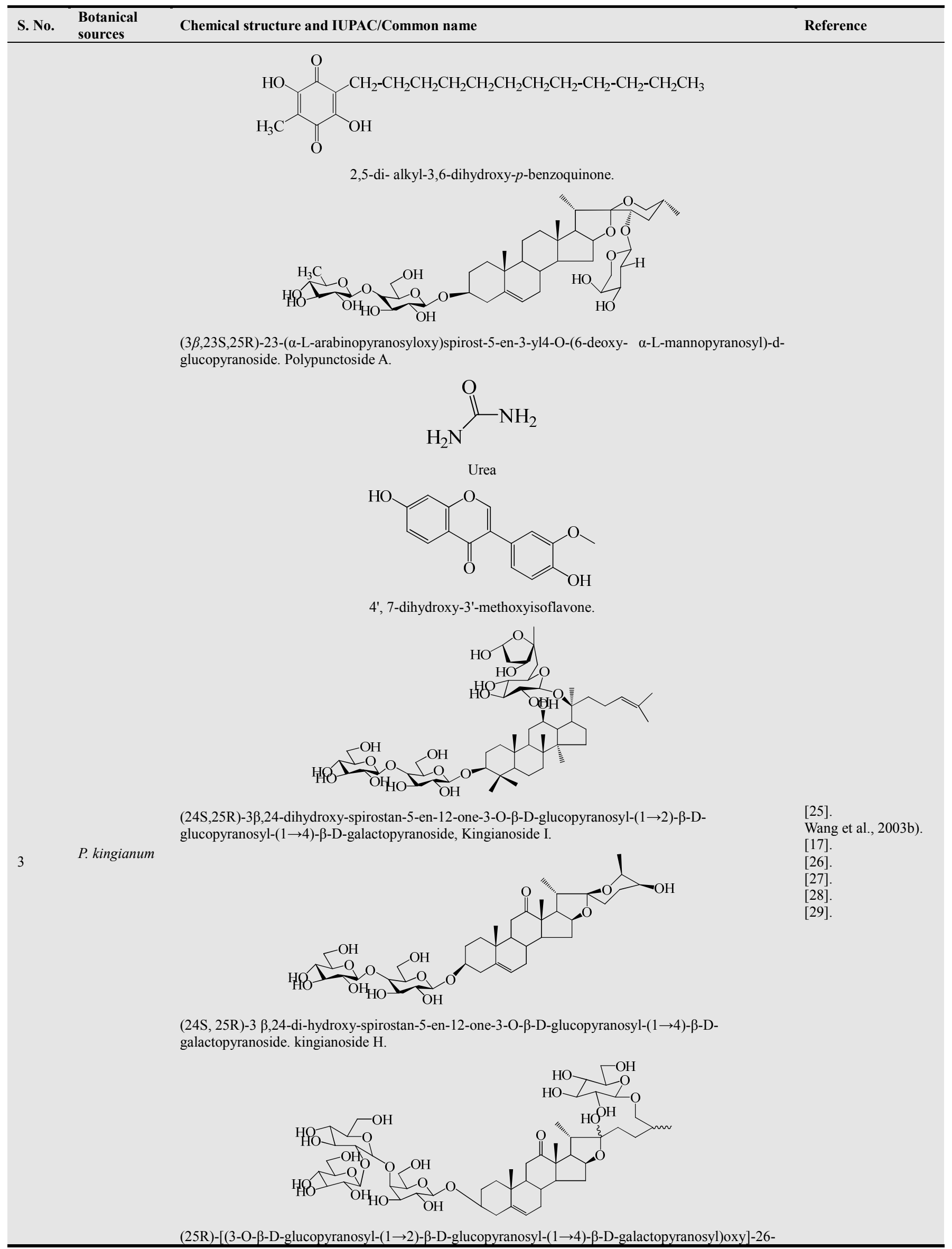




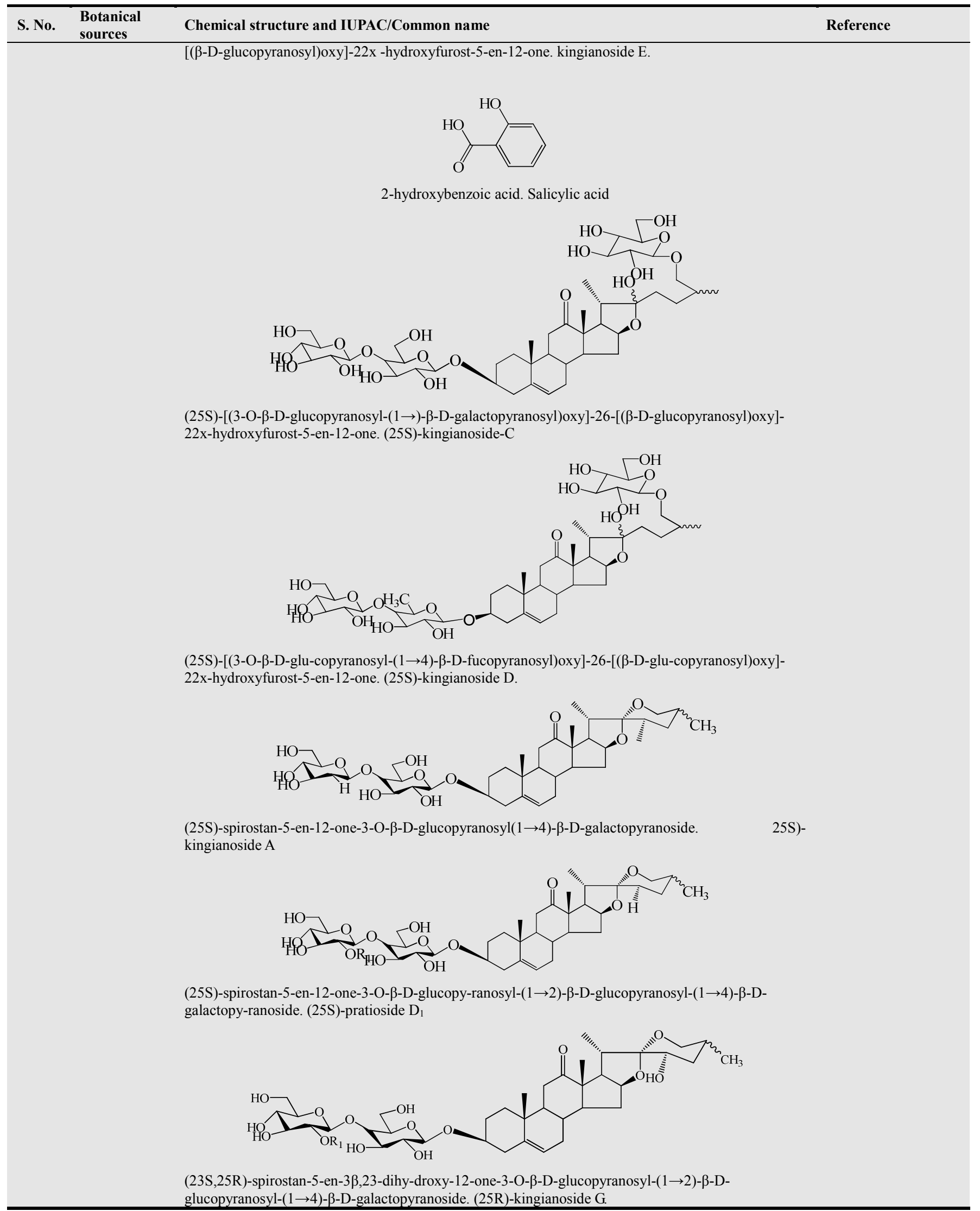




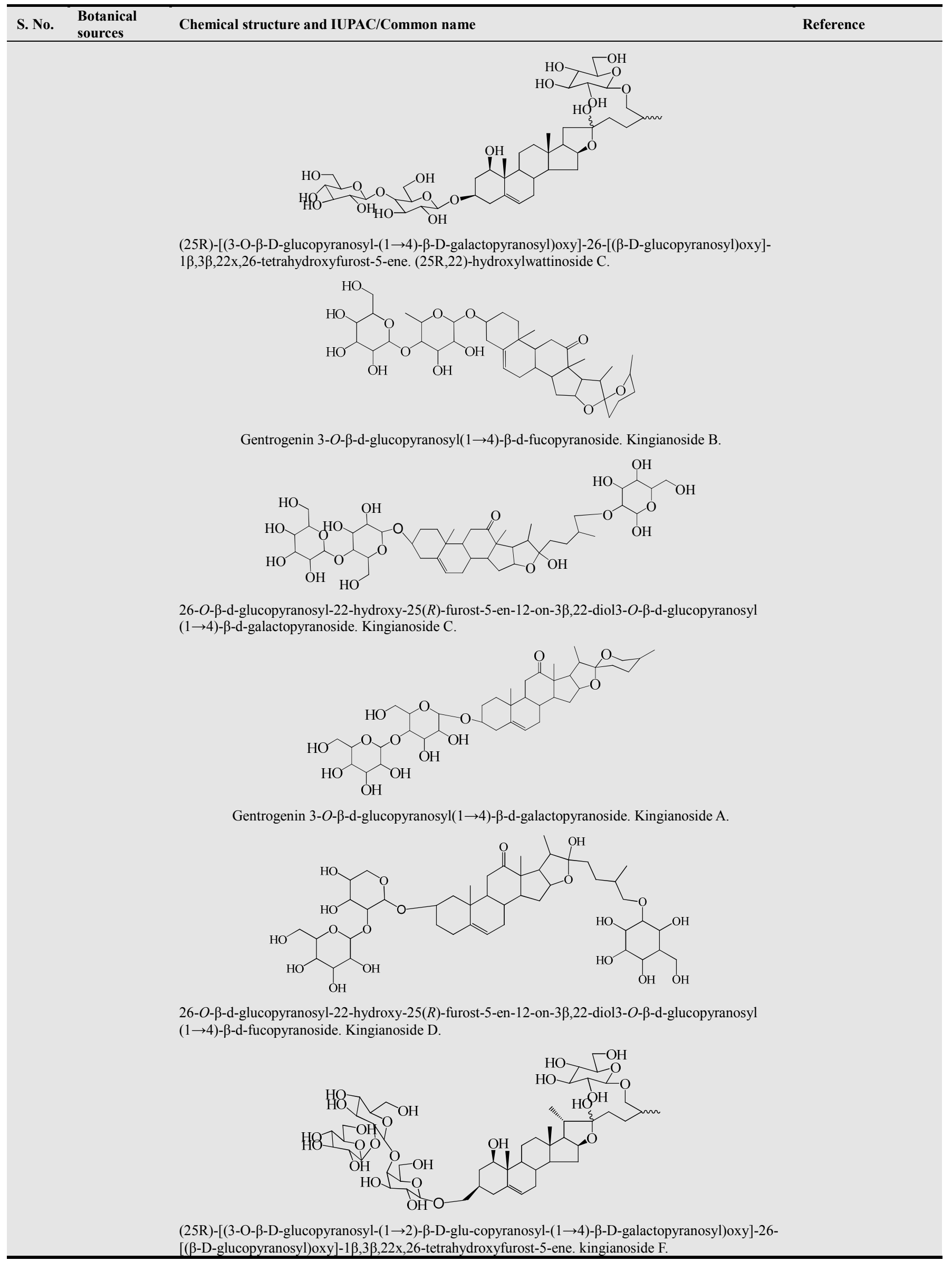




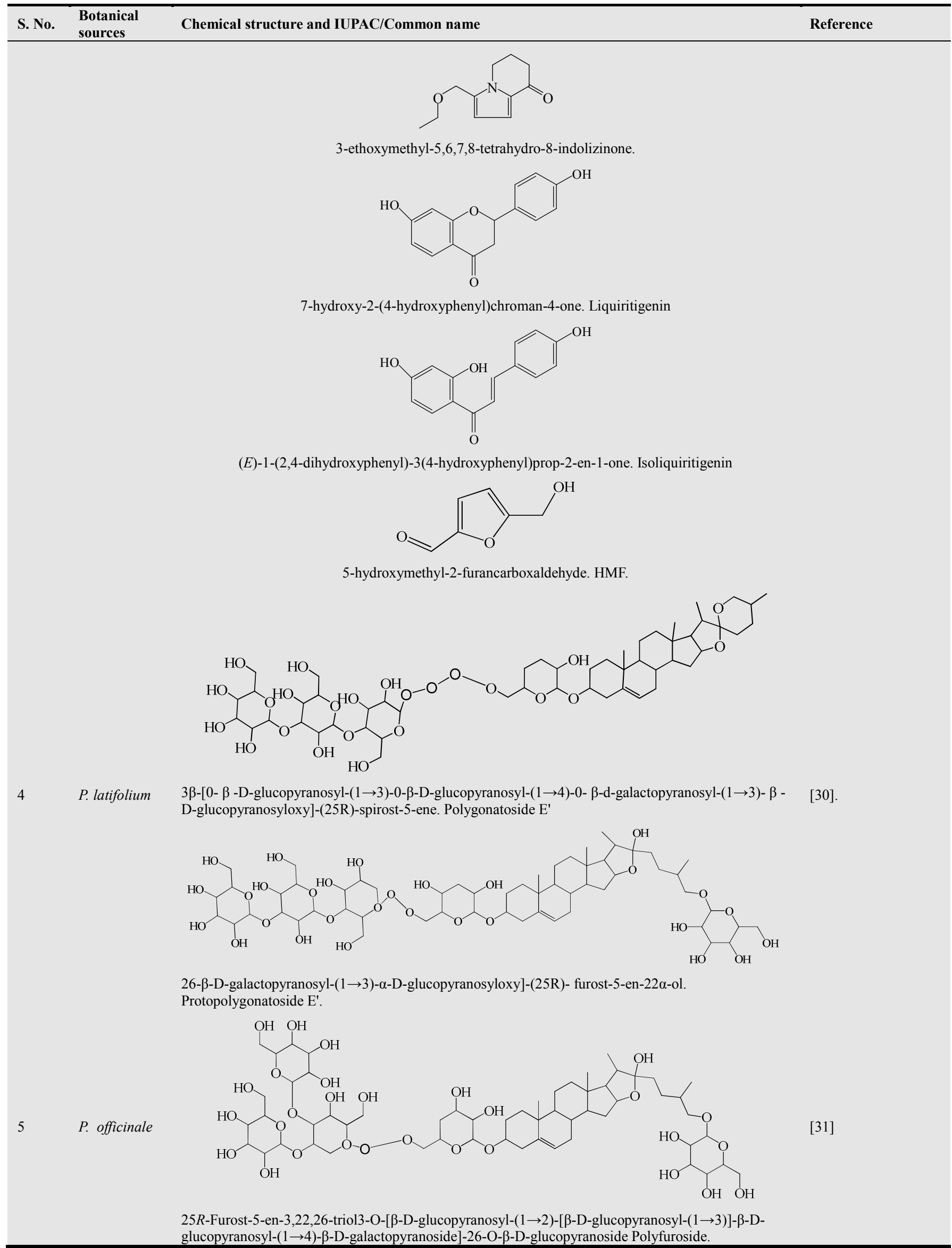




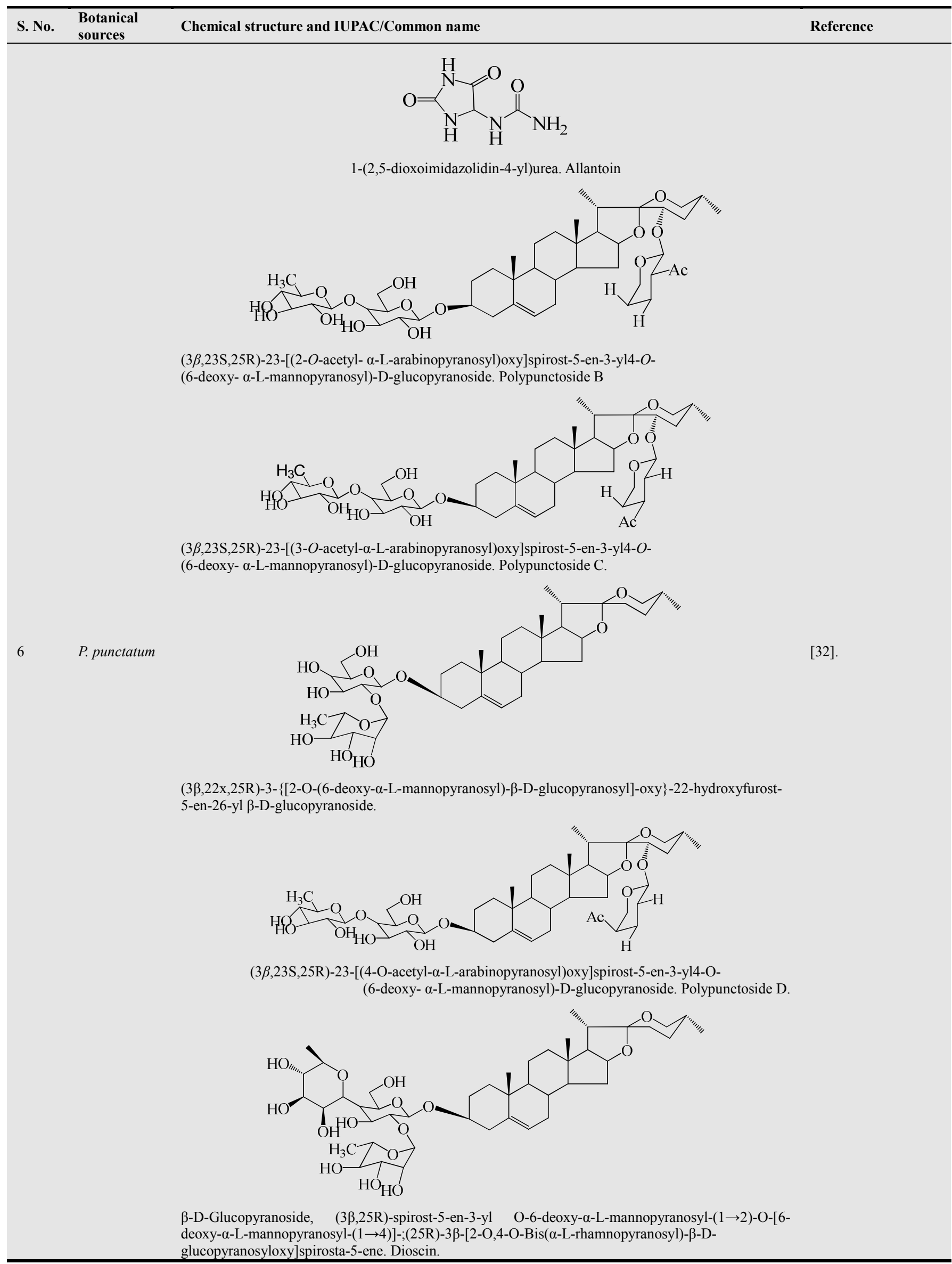




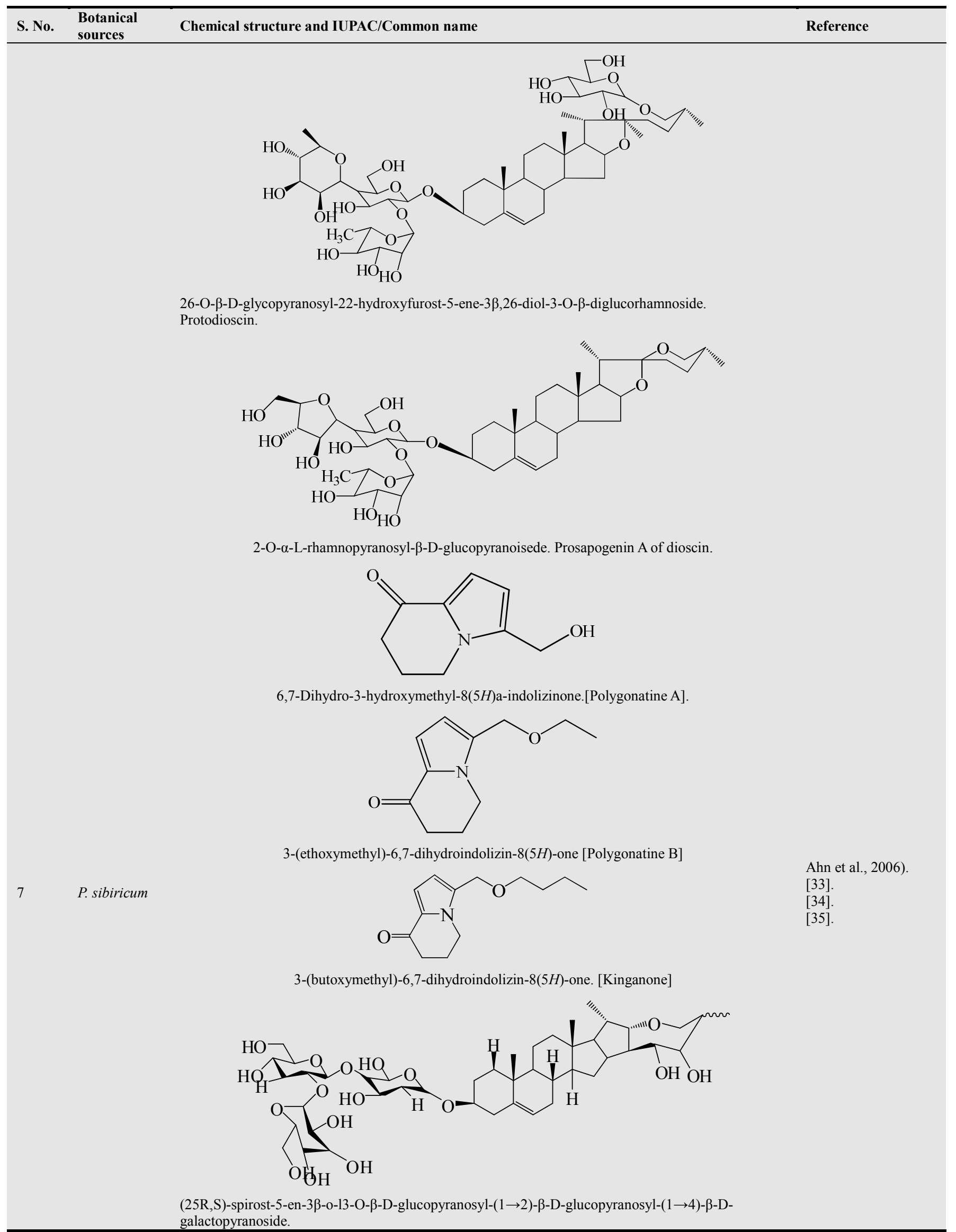




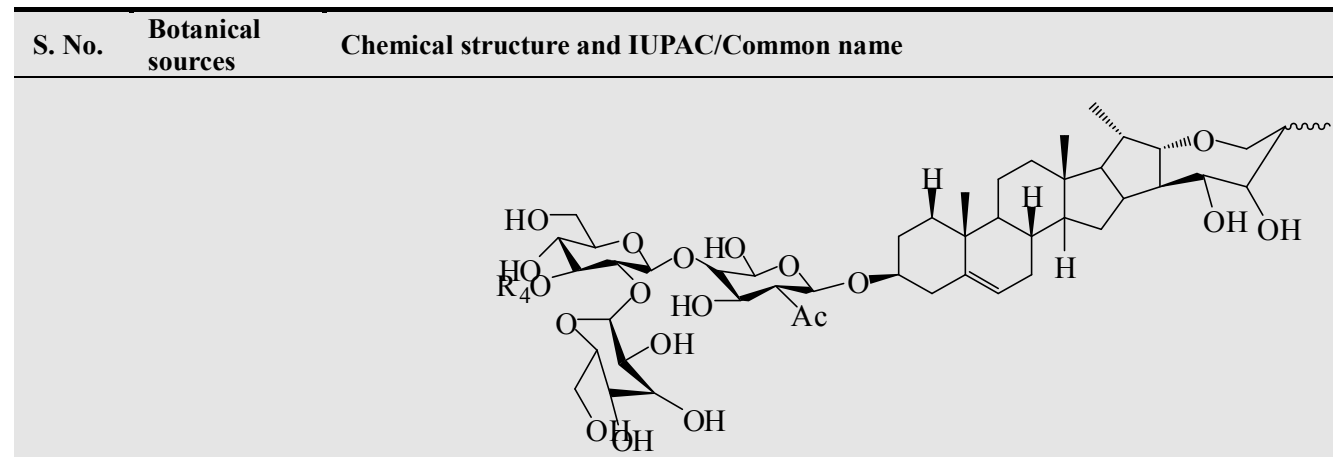

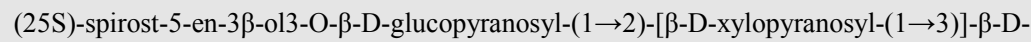
glucopyranosyl-( $(1 \rightarrow 4)-2-\mathrm{O}$-acetyl- $\beta$-D-galactopyranoside.

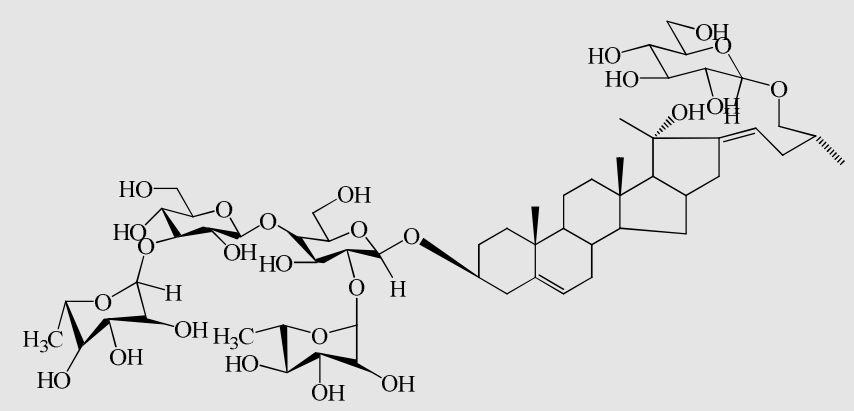

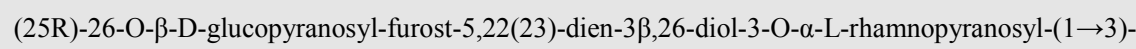
$\beta$-D-glucopyranosyl-( $(1 \rightarrow 4)$-[ $\alpha$-L-rhamnopyr-anosyl-( $1 \rightarrow 2)]-\beta$-D-glucopyranoside.

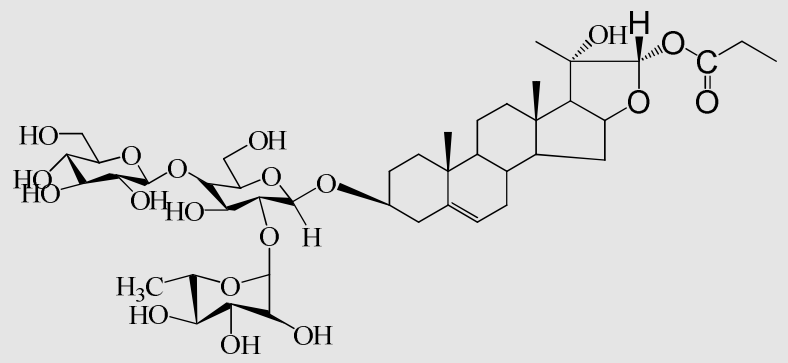

$22 \alpha$-(propionyloxy)-furost-5-en-3 $\beta, 20 \alpha$-diol-3-O- $\beta$-D-glucopyranosyl-( $1 \rightarrow 4$ )-[ $\alpha$-L-rhamnopyranosyl$(1 \rightarrow 2)]-\beta-D-$ glucopyranoside. Polygonoide B.

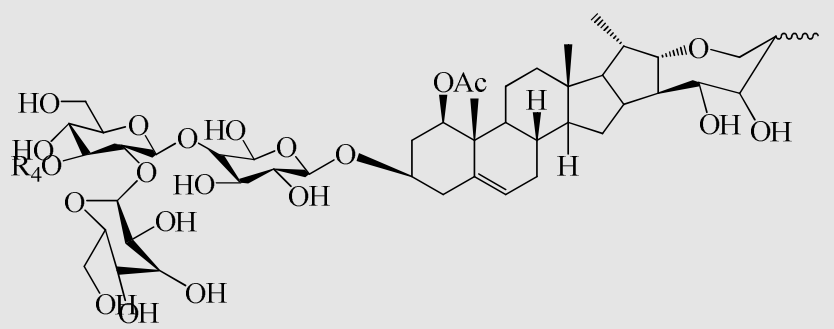

(25S)-1-O-acetylspirost-5-ene-1 $\beta, 3 \beta$-diol3-O- $\beta$-D-glucopyranosyl-(1 $\rightarrow 2)$-[ $\beta$-D-xylopyranosyl$(1 \rightarrow 3)]$ - $\beta$-D-glucopyranosyl-( $1 \rightarrow 4)-\beta$-D-galactopyranoside.Neosibiricoside B.

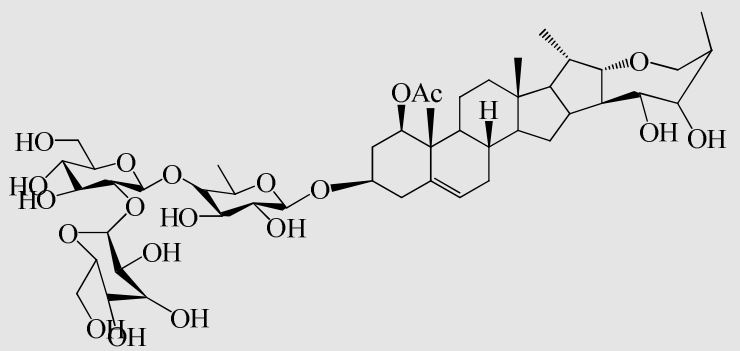

(23S,24R,25R)-1-O-acetylspirost-5-ene-1 $\beta, 3 \beta, 23,24-$ tetrol3-O- $\beta$-D-glucopyranosyl-( $1 \rightarrow 2)-\beta-D-$ glucopyranosyl-( $(1 \rightarrow 4)-\beta$-D-fucopyranoside. Neosibiricoside A. 


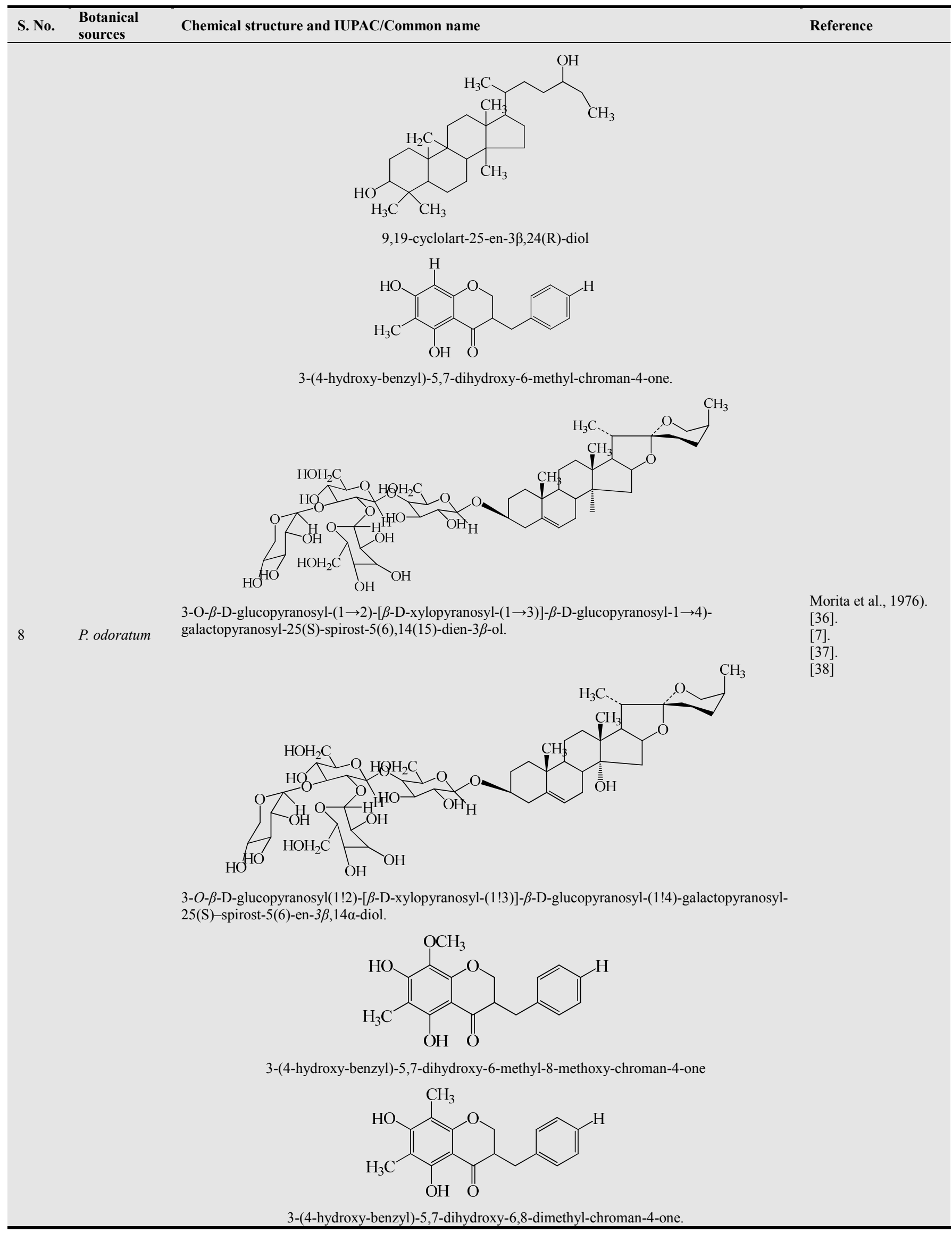




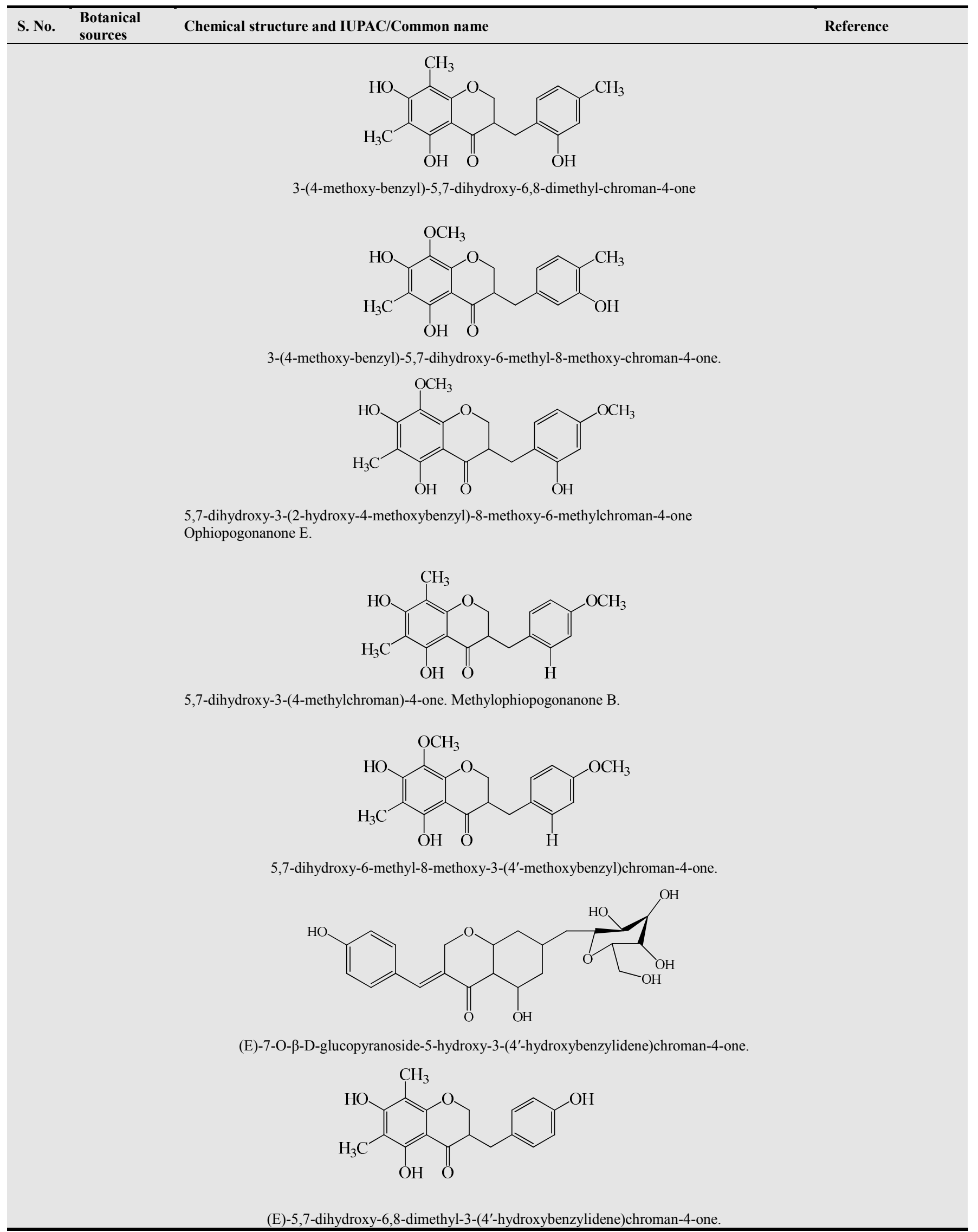




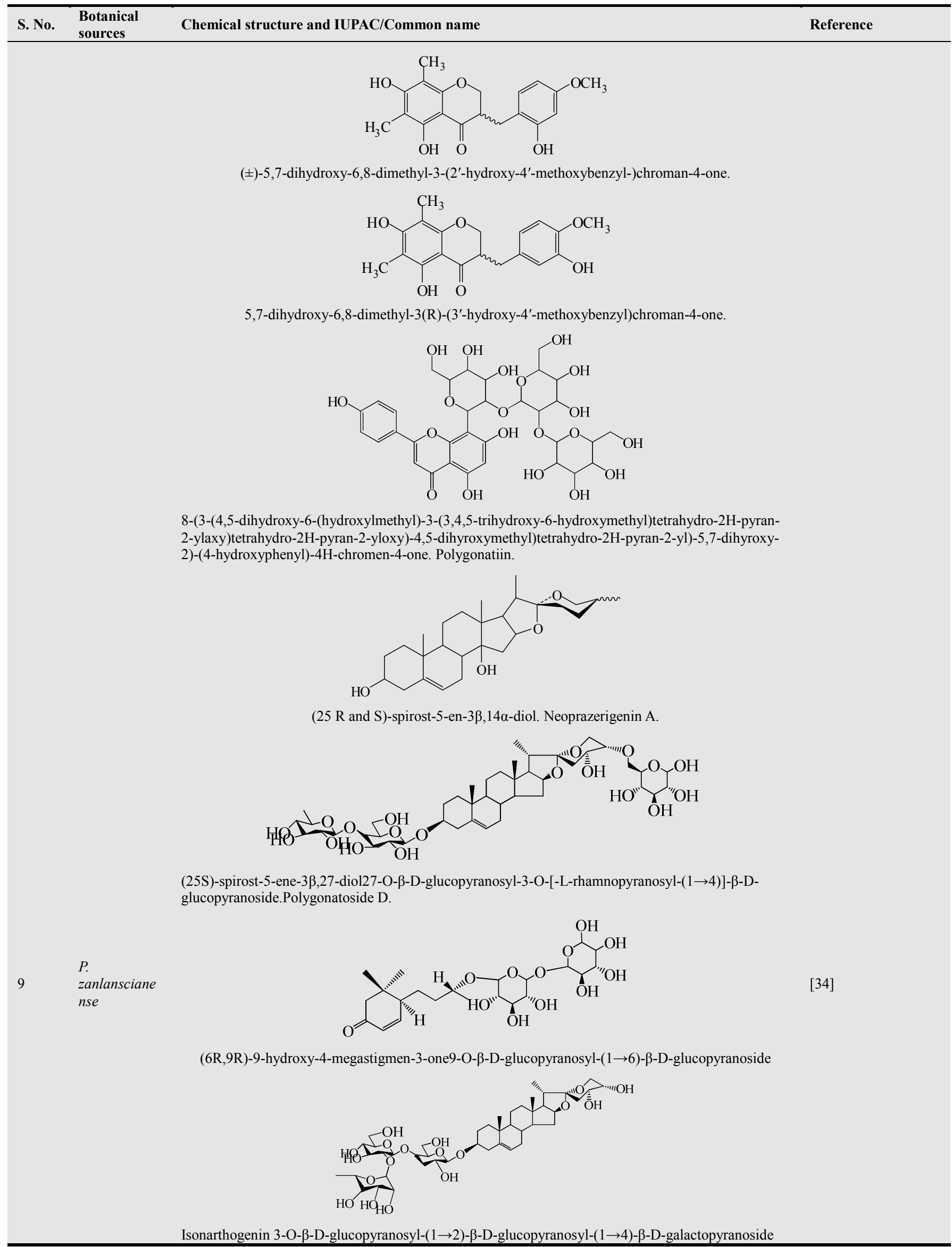




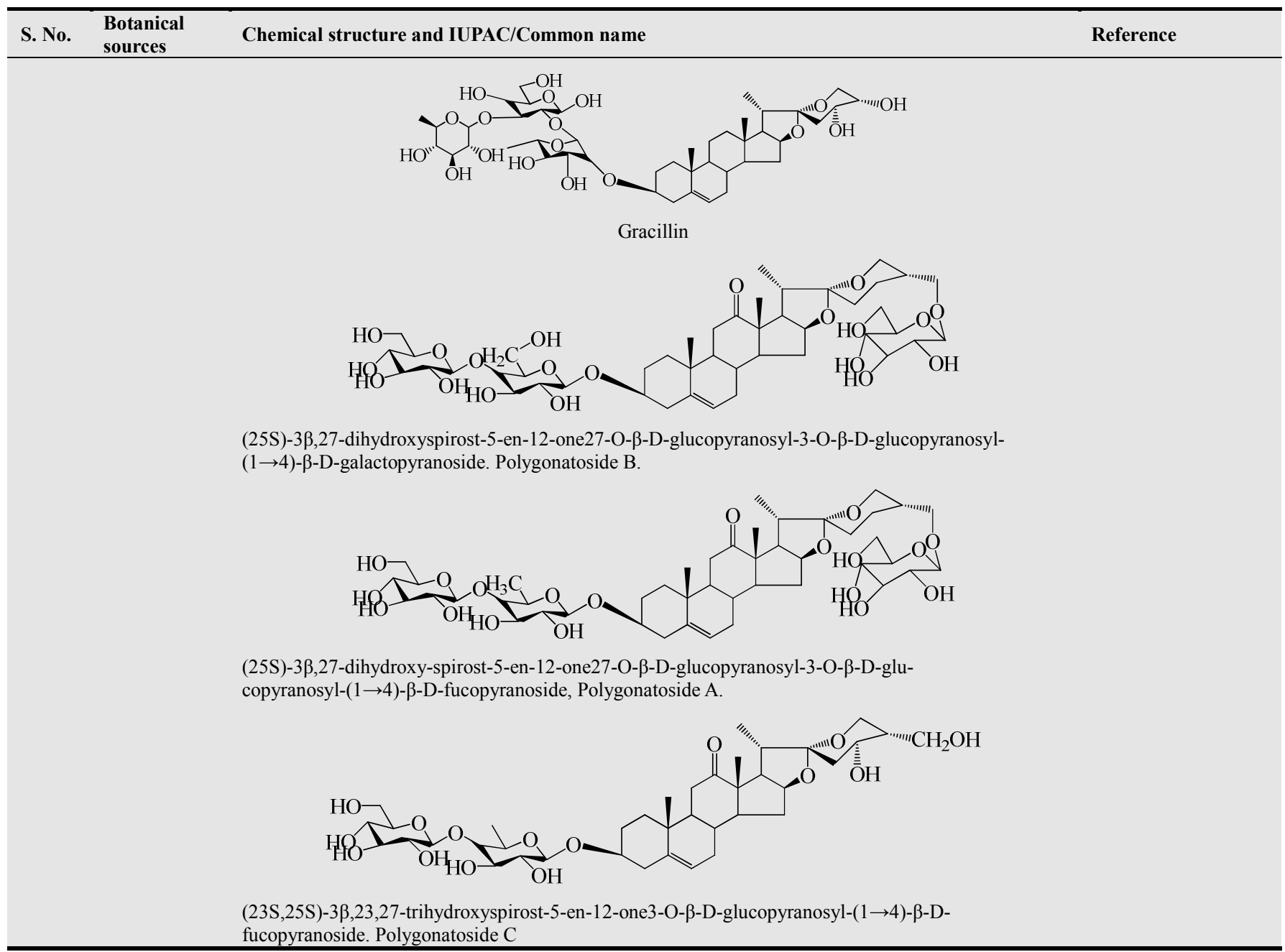

\section{Conclusion}

In conclusion, the genus Polygonatum has approximately 60 species out of which only 9 are explored yet. The remaining species of the genus could be useful sources of natural therapeutic agents; therefore, it is, strongly recommended to subject the rest of species to phytochemical studies in order to discovery molecules of clinical utility.

\section{References}

[1] Szczecinska M, Sawicki J, Polok K, Holdynski C. Comparasion of the three Polygonatum species from Poland based on DNA markers. Annales Botanici Fennici 2006;43:379.

[2] Tamura M. Biosystematic studies on the genus Polygonatum (liliaceae) morphology of staminal filaments and karyology of elevan Eusasian species. Botanische Jahrbücher für Systematik 1993;115:1.

[3] Stewart RR. Flora of West Pakistan, 1972.

[4] Polygonatum. Flora of Pakistan, http://www.efloras.org/florataxon.aspx?flora id=5\&taxon_id= 1263942010
[5] Wang Y, Lu C, Lai G, Cao J, Luo S. A new indolizinone from Polygonatum kingianum. Planta Medica 2003;69:1066.

[6] Wang D, Li D, Zhu W, Peng P. A new C-methylated homoisoflavanone and triterpenoid from the rhizomes of Polygonatum odoratum. Natural Product Research 2009;23:580.

[7] Wang D, Li D, Zhu W, Zhang J, Peng P. Steroidal saponins from the rhizomes of Polygonatum odaratum Natural Product Research 2009;23:940.

[8] Hou JP, Jin Y. The healing power of Chinese herbs and medicinal recipes. New York: The Haworth integrative Healing press, 2005.

[9] Liu B, Peng H, Yao Q, Li J, Van Damme E, Balzarini J, Bao $\mathrm{Jk}$. Bioinformatics analyses of the mannose-binding lectins from Polygonatum cyrtonema, Ophiopogon japonicus and Liparis noversa with antiproliferative and apoptosis-inducing activities. Phytomedicine 2009;16:601.

[10] Liu B, Zhang B, Min Mw, Bian Hj, Chen L, Liu Q, Bao Jk. Induction of apoptosis by Polygonatum odoratum lectin and its molecular mechanisms in murine fibrosarcoma L929 cells. Biochimica et Biophysica Acta (BBA) - General Subjects 2009; 1790:840. 
[11] Liu B, Cheng Y, Zhang B, Bian $\mathrm{Hj}$, Bao Jk. Polygonatum cyrtonema lectin induces apoptosis and autophagy in human melanoma A375 cells through a mitochondria-mediated ROSp38-p53 pathway. Cancer Letters 2009;275:54.

[12] Rafi MM, Vastano BC. Identification of a structure specific Bcl-2 phosphorylating homoisoflavone molecule from Vietnamese coriander (Polygonatum odoratum) that induces apoptosis and G2/M cell cycle arrest in breast cancer cell lines. Food Chemistry 2007;104:332.

[13] Jin J, Zhang Y, Li H, Yang C. Cytotoxic steroidal saponins from Polygonatum zanlanscianense. Journal of Natural Product 2004;67:1992.

[14] Ahn M, Kim C, Yoon K, Ryu M, Cheong J, Chin Y, Kim J. Steroidal Saponins from the Rhizomes of Polygonatum sibiricum. Journal of natural products 2006;69:360.

[15] Jeon S, Lee M, Park Y, Park H, Choi M. Polygonatum rhizoma affects antioxidant defense systems without changing mRNA expression in diet-induced hypercholesterolemic rabbits. Journal of Medicinal Food 2004;7:358.

[16] Pao-Lin H, Kim-Hong G, Ru-Rong W, Chun-Nan L. Benzoquinones, a homoisoflavanone and other constituents from Polygonatum alte-lobatum. Phytochemistry 1997;44:1369.

[17] Wang Y, Mu T, Chen J, SD L. Studies on chemical constituents from the root of Polygonatum kingianum. Zhongguo Zhong Yao Za Zhi. 2003;28:524.

[18] Chiabrando C, Castelli MG, Cozzi E, Fanelli R, Campoleoni A, Balotta C, Latini R, Garattini S. Antiinflammatory action of salicylates: aspirin is not a prodrug for salicylate against rat carrageenin pleurisy. European Journal of Pharmacology 1989;159:257.

[19] Yu G, Mulabagal V, Diyabalanage T, Hurtada W, DeWitt D, Nair M. Non-nutritive functional agents in rattan-shoots, a food consumed by native people in the Philippines. Food Chemistry 2008;110:991.

[20] Kim J-S, Kim J-C, Lee S, Lee B-H, Cho KY. Biological activity of 1-2-azetidinecarboxylic acid, isolated from Polygonatum odoratum var. pluriflorum, against several algae. Aquatic Botany 2006;85:1.

[21] Lu M-C, Hsieh M-T, Wu C-R, Cheng H-Y, Hsieh C-C, Lin YT, Peng W-H. Ameliorating effect of emodin, a constitute of Polygonatum multiflorum, on cycloheximide-induced impairment of memory consolidation in rats. Journal of Ethnopharmacology 2007;112:552.

[22] Khan H, Saeed M, Khan MA, Muhammad N, Ghaffar R. Isolation of long-chain esters from the rhizome of Polygonatum verticillatum by potent tyrosinase inhibition. Medicinal Chemistry Research 2013;22:2088.

[23] Khan H, Saeed M, Mehmood MH, Rehman N-u, Muhammad N, Ikram-ul H, Ashraf N, El-Tahir KE, Gilani A-H. Studies on tracheorelaxant and anti-inflammatory activities of rhizomes of Polygonatum verticillatum. BMC complementary and alternative medicine 2013;13:197.
[24] Khan H, Saeed M, Khan MA, Khan I, Ahmad M, Muhammad $\mathrm{N}$, Khan A. Antimalarial and free radical scavenging activities of rhizomes of Polygonatum verticillatum supported by isolated metabolites. Medicinal Chemistry Research 2012;21:1278.

[25] Wang Y, Lu C, Lai G, Cao J, Luo S. A new indolizinone from Polygonatum kingianum. Planta medica 2003;69:1066.

[26] Yu H, Ma B, Kang L, Zhang T, Jiang F, Zhang J, Zou P, Zhao Y, Xiong C, Tan D. Saponins from the Processed Rhizomes of Polygonatum kingianum. Chemical and Pharmaceutical Bulletin 2009;57:1011.

[27] Zhang J, Ma B, Kang L, Yu H, Yang Y, Yan X, Dong F. Furostanol saponins from the fresh rhizomes of Polygonatum kingianum. Chemical and Pharmaceutical Bulletin 2006;54:931.

[28] He-Shui Y, Jie Z, Li-Ping K, Han L-F, Zou P, Zhao Y, Xiong C-Q, Tan D-W, Song X-B, Yu K, Ma B-P. Three New Saponins from the Fresh Rhizomes of Polygonatum kingianum. Chemical and Pharmaceutical Bulletin 2009;57:1.

[29] Xing-Cong L, Chong-Ren Y, Makoto I, Hiromichi M, Ryoji K, Kazuo Y. Steroid saponins from Polygonatum kingianum. Phytochemistry 1992;31:3559.

[30] Kintya PK, Stamova AI, Bakinovskii LB, Krokhmalyuk VV. Steroid glycosides XXI. The structure of polygonatoside $\mathrm{E}^{\prime}$ and protopolygonatoside $\mathrm{E}^{\prime}$ from the leaves of Polygonatum latifolium. Chemistry of Natural Compounds 1978;14:290.

[31] Janeczko Z, Jansson P, Sendra J. A new stereoidal saponin from Polygonatum officinale. Planta medica 1987;53:52.

[32] Yang Q-X, Yang C-R. Cytotoxic Steroidal Saponins from Polygonatum punctatum Chemistry and Biodiversity 2006;3:1349.

[33] Long-Rusun, Li X, Su-Xianwang. Two new alkaloids from the rhizome of Polygonatum sibiricum. Journal of Asian Natural Products Research 2005;7:127.

[34] Jin J-M, Zhang Y-J, Li H-Z, Yang C-R. Cytotoxic steroidal saponins from Polygonatum zanlanscianense. Journal of Natural Product 2004;67:1992.

[35] Yi-Fen W, Chun-Hua L, Guo-Fang L, Jian-Xin C, Shi-De L. A New Indolizinone from Polygonatum kingianum. Planta medica 2003;69:1066.

[36] Qin H, Li Z, Wang P. A new furostanol glycoside from Polygonatum odoratum. Chinese Chemical Letters 2003;14:1259.

[37] Qian Y, Liang JY, Qu W, Che Y. Two new homoisoflavanones from Polygonatum odoratum (Mill.) Druce. Chinese Chemical Letters 2010;21:706.

[38] Zhang H, Yang F, Qi J, Song X, Hu Z, Zhu D, Yu B. Homoisoflavonoids from the Fibrous Roots of Polygonatum odoratum with Glucose Uptake-Stimulatory Activity in 3T3L1 Adipocytes. Journal Natural Product 2010;73:548. 